\title{
A Bauhaus arde na fogueira de Tom Wolfe
}

\author{
Regina M. Prosperi Meyer
}

Em 1919, no seu primeiro manifesto, Gropius, como diretor da Bauhaus, dizia: "O que é arquitetura? A expressão cristalina dos mais nobres pensamentos do homem, seus fervores, sua humanidade, sua fé, sua religião!". Não há dúvida, uma definição inflamada! E serve como uma luva às intenções de Wolfe. O caráter obstinado, vital e religioso que cercava a atuaçăo da Bauhaus na Alemanha ao atravessar o Atlântico traduzse na visão de Wolfe em usurpação e constrangimento. A suprema meta e missão da Bauhaus, de "servir ao desenvolvimento da habitação, do mais simples utensílio doméstico até a casa acabada", tornou-se, na interpretação de Wolfe, o maior "martírio" do povo americano. Wolfe propõe a todos uma reflexão sobre este "abuso" da arquitetura moderna. A conjugação rimada do título original our house com "Bauhaus" deixa claro que ele se dirige ao usuário. E, pelo relato, ninguém escapou. Burgueses e nãoburgueses, a todos coube uma parte neste infortúnio.

$\mathrm{O}$ texto induz num primeiro momento a uma leitura algo indignada. Assim como os manifestos de Gropius, o tom é inflamado e às vezes excessivamente sarcástico Mas, no correr das páginas, a indignação arrefece cedendo lugar a uma leitura divertida. Seria injusto dizer que $\mathrm{Da}$ Bauhaus ao nosso caos atrai somente pela fina ironia de Wolfe e pelo anedotário abundante. Há na verdade, por trás da intenção de atiçar as opiniões, uma ambição de avaliar a arquitetura moderna e sobretudo de introduzir nesta avaliação o papel da arquitetura e dos arquitetos americanos.

Abrindo o livro, Wolfe causticamente pergunta: "O Bela, dos céus infinitos, dos louros trigais ondulantes, existirá outro lugar na terra em que tanta gente rica e poderosa tenha pago e tolerado tanta arquitetura que detesta do que dentro de suas fronteiras?". Os Estados Unidos provavelmente responderiam, em nome da verdade, que efetivamente não se tem notícia de abuso maior. Ainda em nome da verdade acrescentariam (e esta segunda parte fere a tese de Wolfe) que os maltratos foram infligidos tanto pelos "deuses brancos" desembarcados da Europa no final dos anos 30, quanto pelos próprios arquitetos nativos, filhos também da "bela dos céus infinitos".

$\mathrm{O}$ balanço que Wolfe faz da arquitetura moderna nos Estados Unidos vai muito além Divulgação da polarização entre brancura-leveza-enxu-

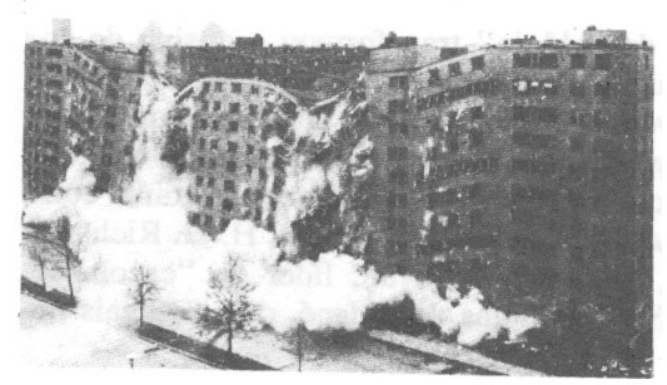
teza-nudez-despojamento versus cor-aconchego. Wolfe na verdade traça um itinerário da arquitetura americana baseado na hipótese de que este percurso foi altamente determinado pela chegada em 1937 do mais importante arquiteto europeu daquele momento: Walter Gropius. O "Príncipe de Prata", denominação que Wolfe toma emprestądo de Paul Klee, é o primeiro "deus branco" a desembarcar. Fugindo à expan-
REGINA M. PROSPERI MEYER é professora da Faculdade de Arquitetura e Urbanismo (FAU) da USP.

Da Bauhaus ao nosso caos (From Bauhaus to our house), de Tom Wolfe traduçăo de Lia Wyler. Rio, Editora Rocco, 104 pp.

O Conjunto Habitacional de Pruitt-Igoe em Saint Louis, 15 de julho de 1972

(1) 


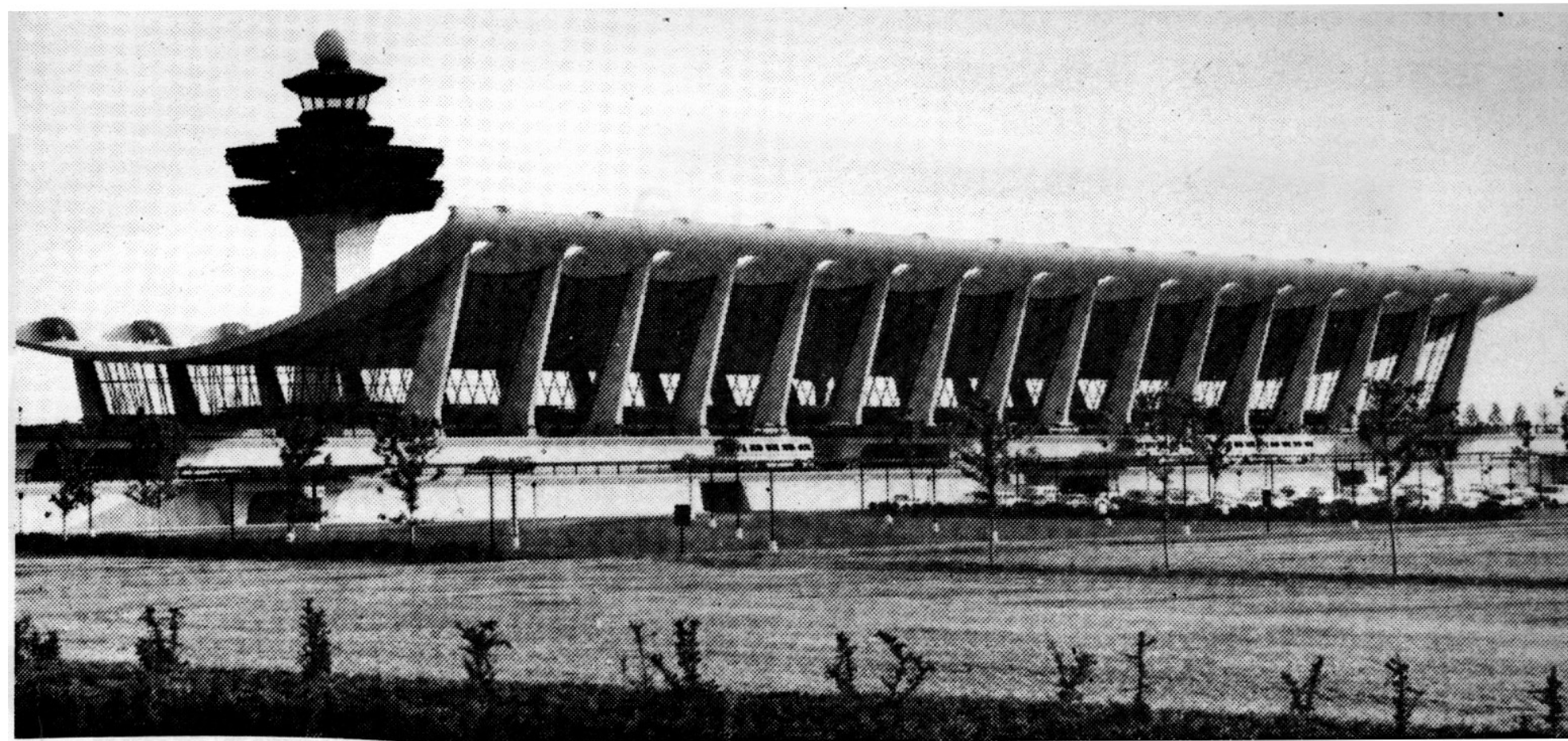

O teto alado de Eero Saarinen, para o Dulles International Airport (à esquerda) e seu terminal em forma de águia para a. TWA, que enfureceram os modernistas são nazista, vieram se juntar a Gropius M. Breuer, Albers, Moholy-Nagy, Mies Van der Rohe. Era a Bauhaus desembarcando e realimentando na visão de Wolfe o "complexo colonialista" americano, que "paralisa mais que um golpe de luta livre".

Os Estados Unidos são então um misto de selva e paraíso. Selva porque habitados por "selvagens" que se curvam de forma tacanha e pueril diante dos "deuses brancos" vindos do céu. E paraíso, porque oferecem a estes deuses refugiados muito mais do que uma boa acolhida. Oferecem oportunidade de trabalho. Efetivamente, relata Wolfe: "Gropius foi nomeado diretor da Escola de Arquitetura de Harvard e M. Breuer se reuniu a ele. Moholy-Nagy abriu a Nova Bauhaus que acabou se transformando na Chicago Institute of Design. Albers abriu uma Bauhaus rural nas montanhas da Carolina do Norte, no Black Mountain College. Mies instalou-se como decano de arquitetura no Armours Institute de Chicago".

Esta absorção atesta à primeira vista uma enorme capacidade da sociedade americana de reconhecer as qualidades dos recém-chegados e de apropriar-se da experiência vital da Bauhaus. Entretanto, Wolfe alerta que esta mudança de rumo empreeridida pela arquitetura americana em apenas três anos não a conduziu a um estimulante período de crescimento teórico e prático. Para Wolfe, "na terra do complexo colonialista" os "deuses brancos" vieram "para governar, em pessoa, a grande Nigeriazinha das Artes”. O estrago que a guerra na Europa provocava indiretamente nos Estados Unidos, segundo Wolfe, era considerável e não se restringia à arquitetura. Os artistas plástıcos também procuravam o abrigo americano. Em fins da década de 30 e início da de 40 chegaram: Léger, Mondrian, Modigliani, Chagall, Max Ernst, André Breton, Yves Tanguy. E, no caso dessas "estrelas" das artes (deuses só os arquitetos!), a América abrigou também as suas rivalidades. O preço pago pelos Estados Unidos, segundo Wolfe, por tanta generosidade foi alto: "A Cena Americana e a pintura social realista dos anos 30 desapareceram para nunca mais reaparecer”.

O "Príncipe de Prata" agora "governador da colônia" transformou o ensino de arquitetura. "Transformou" talvez não seja a palavra adequada para descrever a visão de Wolfe. Para ele houve uma apropriação: "As velhas tradições das Belas Artes tornaramse heresia, bem como o legado de Frank Lloyd Wright, que para começar mal chegara às escolas de arquitetura. Em três anos, tudo que se poderia chamar de importante contribuição americana à arquitetura contemporânea - de autoria de Wright, H. H. Richardson, criador do romântico-rústico americano, ou Louis Sullivan, líder da "escola de Chicago" de arranha-céus - tinha caído ao nível das notas de rodapé, dos matagais do ibid. 


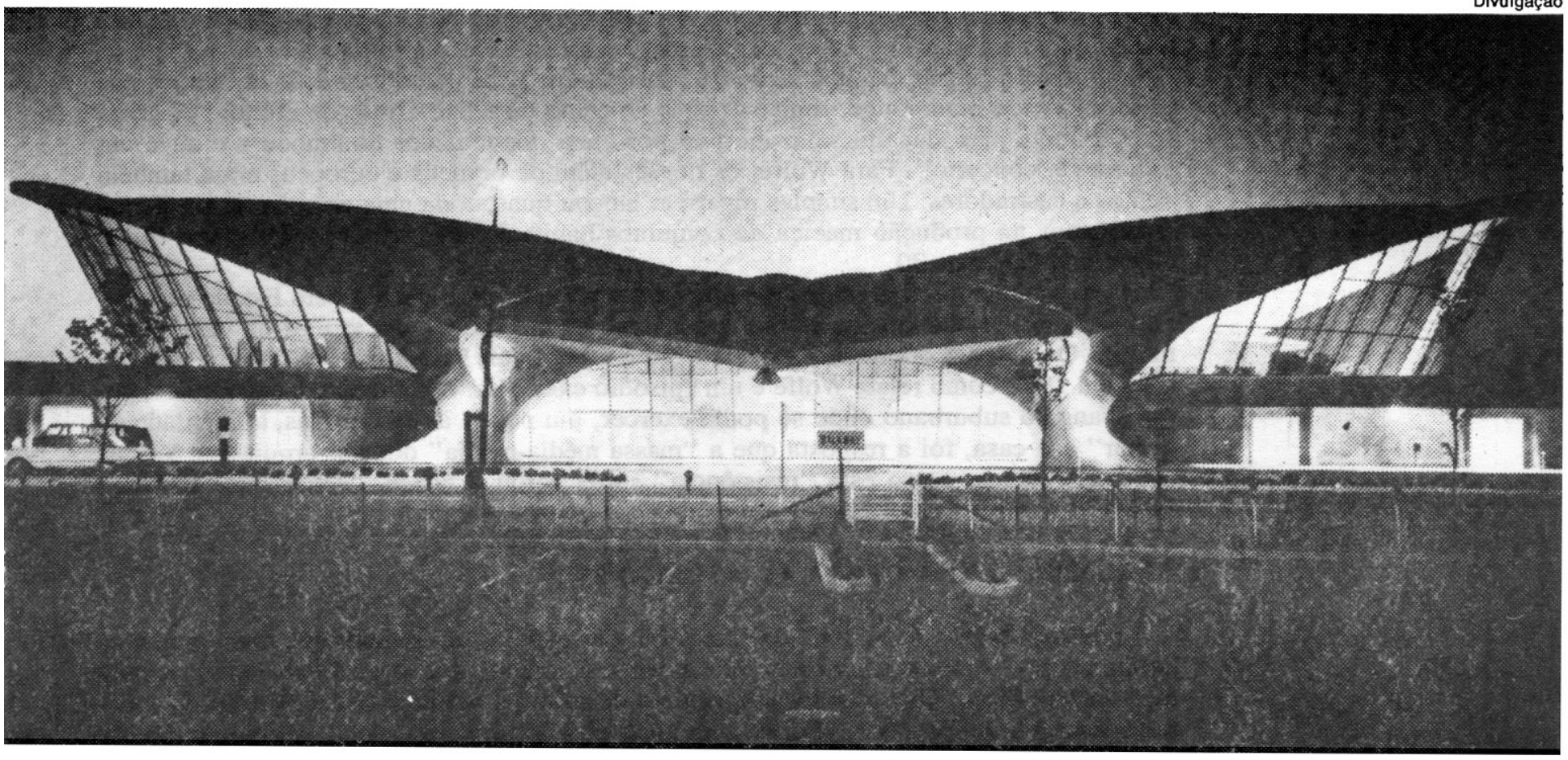

\section{OS DEUSES FORASTEIROS}

Assimilados e organizados em redutos, os "deuses brancos" comanndam a arquitetura americana. Os departamentos de arquitetura das universidades assumiram as características destes "redutos", espécie de santuários de onde emanava a verdade sob forma de ensino, textos e projetos. E Wolfe mostra que a partir destas cidadelas competiu-se em dois níveis: "Não havia meramente a competição imemorial para receber encomendas e ter uma oportunidade de mostrar ao mundo o que se podia fazer construindo edifícios e vendo-os subir. Havia também a competição puramente intelectual das teorias". Veremos no final do período descrito por Wolfe a importância desta postura no confronto entre arquitetura americana e arquitetura européia. Voltando ao texto de Wolfe: "Uma vez que a divindade da arte habitava os redutos e nenhum outro lugar, não havia nada que impedisse um homem inspirado e genial, um sacerdote, um hierofante, um Duns Scotus, de fazer seu nome sozinho sem sequer abandonar o recinto sacerdotal. Com isso nasceu mais um fenômeno único: o arquiteto famoso que construía pouco ou nada".

Esta afirmação de Wolfe além de seu evidente interesse é também estratégica, pois introduz na cena um "deus branco" que não foi para a América e que mesmo à distância interferia na arquitetura americana: Le Corbusier.

Sua "escola", seu "ismo" eram sem dúvida a antítese à distância de Frank Lloyal Wright. Wolfe dá a dimensão pessoal e malévola da disputa ao relatar os comentários irritados de Wright toda vez que Le Corbusier terminava um edifício: "Bom, agora que terminou um edifício, vai escrever quatro livros sobre ele". Na verdade, a disputa entre o funcionalismo/racionalismo de Le Corbusier e o organicismo de F. L. Wright foi um episódio essencial da arquitetura moderna. Por alguma razão, entretanto, Wolfe não aprofunda esta discussão. Limita-se a descrever Le Corbusier como um agitador cultural sempre disposto a uma declaração brilhante, veemente e incisiva do que deveria ser a arquitetura e as cidades: "construiu a Cidade Radiosa no crânio". Em contraponto, Wolfe mostra F. L. Wright como mais consistente, lutando para implantar uma arquitetura "totalmente nova e totalmente americana, nascida do solo e do espírito americano do Meio-Oeste". Wright sofria, e Wolfe seguramente ainda sofre, ao pensar que no final dos anos 30 a "nova arquitetura americana" viera diretamente da Alemanha, Holanda e França através de Le Corbusier. O paradoxo era enorme. Em pleno "século americano", quando o mundo contempla os Estados Unidos e, como diz Wolfe, "ora com inveja, ora com nojo mas sempre com assombro", a sua arquitetura vive sob tutela. E, o

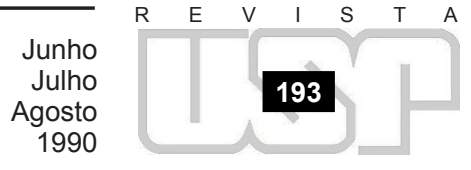


que é pior, uma tutela alienadora pois nos redutos transplantados pregava-se less is mo$r e$ quando a palavra de ordem das demais manifestaçōes da cultura americana aponta para uma permanente demonstração de exuberância. Uma boa observação de Wolfe, que poderia ter ido mais longe, limita-se a ser somente uma linda frase de efeito: "A gente se preparava para dar um salto incrível por cirna dos telhados do mundo - e ouve um pigarro de concerto". Para Wolfe, os deuses além de brancos e europeus eram também velhos e castradores. Um simples pigarrear lançou quase toda uma geração de arquitetos americanos na produção maciça de conjuntos habitacionais populares, programa típico da Europa dos anos 20.

Desta incursão à "habitação-popular-multifamiliar" patrocinada pelo Estado não saíram vencedores. Os conjuntos não representaram um avanço em termos de vida comunitária. O exemplo dramático do Pruitt-Igo em St. Louis inaugurado em 1955 e dinamitado em 1972 como relata Wolfe é um episódio exemplar. A fuga pará os subúrbios, para o bangalô suburbano onde se podia exercer, um pouco às escondidas, a liberdade de "criar" sua casa, foi a resposta que a "massa média-média" deu aos arquitetos. Vamos ver mais adiante como esta "resistência" surda gerou o kitsch, "estilo" que indiretamente R. Venturi vai redimir.

\section{Abalando a estrutura: Os apóstatas}

Entre as "caixas de vidro" de Mies Van der Rohé e seu seguidores, e os conjuntos habitacionais populares, a arquitetura americana chegou aos anos 50 abalada mas com alguma esperança. Os apóstatas começam a desafiar os redutos. O surgimento da apostasia tem grande interesse. Wolfe, com a escolha do termo apóstata, reforçou o caráter religioso dos redutos dedicados ao culto do estilo internacional. Romper com um reduto, dispensar o "consenso" de que falava Mies teve um preço. Wolfe descreve mais as vicissitudes deste rompimento, do que as obras que dele resultaram. $\mathrm{O}$ que interessa Wolfe é mostrar que finalmente a nação mais poderosa da Terra "havia encontrado a sua expressão arquitetônica". Os dois grandes apóstatas eram E. D. Stone e Eero Saarinen. As duas obras, instrumentos da apostasia, eram a Gallery of Modern Art, de Stone, o Dulles International Airport e o Teminal da TWA, ambos de Saarinen.

Feitá a cisão tratava-se então de caracterizá-la. Do lado dos apóstatas ficou, além do anátema e dos adjetivos "burguês" e "provinciano", a produção alta e o sucesso comercial. Do outro, nos redutos, ficou a "pureza", o "não-burguês", a vida acadêmica, os ideais e o corolário de tudo isso - poucas obras. Assim divididos, e com uma aparente vantagem na disputa, apesar da coragem e da envergadura de suas obras, os apóstatas não chegaram a reverter o processo: "Já não bastava construir prédios extraordinários para o mundo ver. $\mathrm{O}$ mundo pode ésperar. Agora era necessário ganhar a competição que se realizava unicamente no âmbito da arquitetura acadêmica". A batalha seguinte, protagonizada pelos escolásticos, levará em conta a experiência dos apóstatas.

A nova estratégia dos escolásticos aconselhava a "deixar pra lá a construção de edifícios" e buscar discutir as teorias, os princípios, as doutrinas. Situaram o combate no coração dos redutos. O centro da disputa passa a ser então um livro e não um edifício. Wolfe vibra com a estratégia e com o texto: "Complexity and contradiction in architecture" de Robert Venturi, publicado em 1966, tem o tom de manifesto, porém "suave", pontua Wolfe. Venturi é direto: "Gosto de complexidade e contradição em arquitetura. Não gosto da incoerência ou arbitrariedade da arquitetura incompetente nem das preciosas filigranas do pitoresco ou do expressionismo". Wolfe traduz para que fique tudo bem claro: "Eu tanto quanto vocês, dirigindo-se aos deuses brancos, sou contra o que é burguês (pitoresco, precioso, intrincado, arbitrário, incoerente e incompetente)". E, com grande acerto na escolha, Wolfe cita mais uma frase do texto de Venturi: "Falo de uma arquitetura complexa e contraditória baseada na riqueza e ambigüidade da experiência moderna, inclusive naquela experiência que é inerente à arte". O "suave" e "brilhante" manifesto de Venturi, conclui Wolfe com indisfarçável entusiasmo, condu. ziu o modernismo à sua era escolástica e ao pós-modernismo. E ainda por cima uma escolástica irônica, tão ao gosto de Wolfe - "a estratégia de Venturi era violar o tabu sem o violar. Usou tijolos aparentes (burguês) na parte superior da fachada da Guild House - afinal era apenas um tijolo escuro especialmente escolhido para combinar com os tijolos 'enfarruscados de smog' das decadentes habitações operárias à volta (não-burguês). Colocou uma enorme coluna (burguês) na entrada - mas afinal não possuía or- 

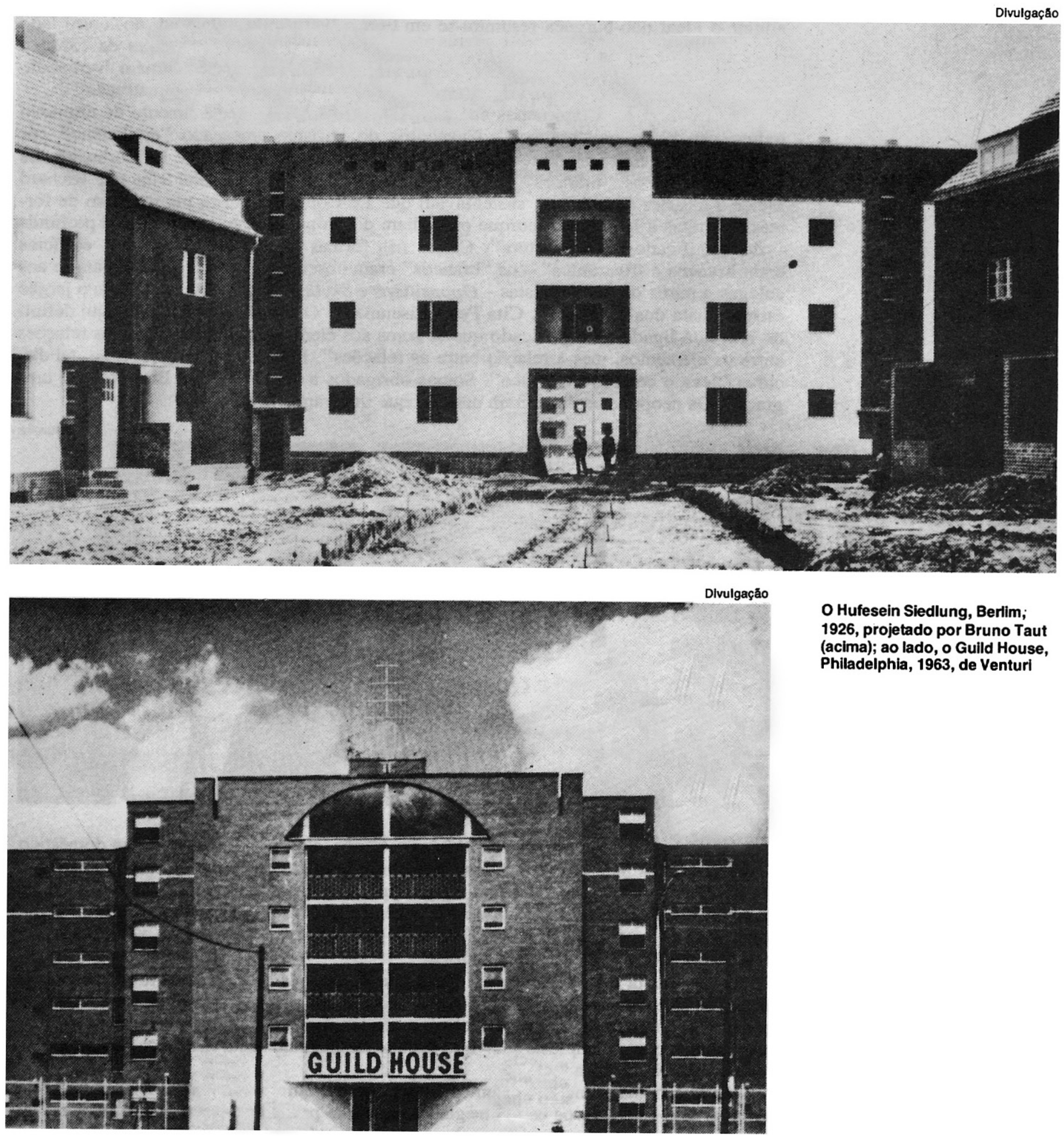

O Hufesein Siedlung, Berlim; 1926, projetado por Bruno Taut (acima); ao lado, o Guild House, Philadelphia, 1963, de Venturi

natos (não-burguês), nem capitel (não-burguês), nem frontão (não-burguês). Não a assentou de lado, mas bem no meio da entrada, fazendo-a perder a imponência (burguês)...".

Não havia dúvida, e o próprio entusiasmo de Wolfe o deixa transparecer - os redutos estão ameaçados. Quase identificado com Venturi, o agente da desforra, Wolfe relembra os pontos vulneráveis dos redutos identificados em "Complexity and contradiction": "primeiro a pavorosa solenidade e exagerada seriedade, segundo, a idade e distanciamento da vida moderna". E, indo mais fundo na observação e na comparação entre as duas abordagens, Wolfe faz uma afirmação interessante: "a abordagem de Mies para 


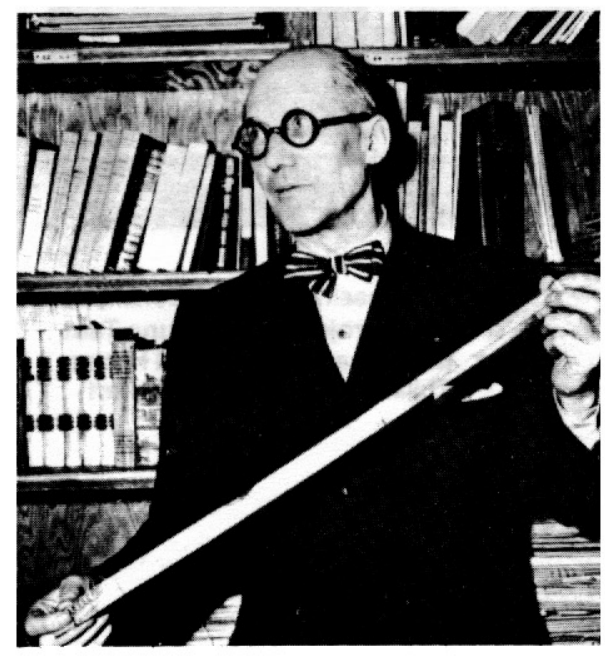

atingir o ideal não-burguês resumira-se em tirar o 'vernáculo industrial' do 'outro lado da sociedade', nas palavras de Venturi, e introduzi-lo nas 'áreas nobres da cidade'. Venturi estava fazendo o mesmo só que atualizando o processo. Usava o "vernáculo comercial' (comercial de Las Vegas) e o "vernáculo do empresário da construção" .

A luta avançava. Com menos entusiasmo Wolfe descreve o nascimento de um novo reduto em 1972: os "brancos". Cavaleiros do purismo ameaçado "sutilmente" por Venturi vieram em clima de restauração reforçar a liderança teórica de Le Corbusier. Os neopuristas ou os “brancos”, P. Eisenman, Michael Graves, John Hejouk, Richard Meier e Charles Gwathmey, sustentavam que Le Corbusier abrira um universo de formas "corretas e inevitáveis porque procediam do próprio cerne - da estrutura profunda - do significado da arquitetura". Claros nas formas arquitetônicas - "seus edifícios eram brancos e frustrantes" - os "brancos" eram obscuros no discurso. Dirigiam-se ans colegas a partir de duas revistas - Oppositions e Skyline. Wolfe diverte-se com o jargão estruturalista dos "brancos". Cita Peter Eisenman: "O significado sintático aqui definido não está ligado ao significado que se soma aos elementos ou às verdadeiras relações entre os elementos, mas à relação entre as relações". E Wolfe parece ter razão, tal discurso "leva o cérebro de roldão". Somos obrigados a concordar que Eisenman "é uma graça”. Os neopuristas divertiram mais do que irritaram Wolfe.

Da esquerda para a direita: Le Corbusier, o "sr. Purismo"; Ludwig Mies van der Rohe, o

"Deus Branco n' 2"; Walter Gropius, o "Príncipe de Prata"
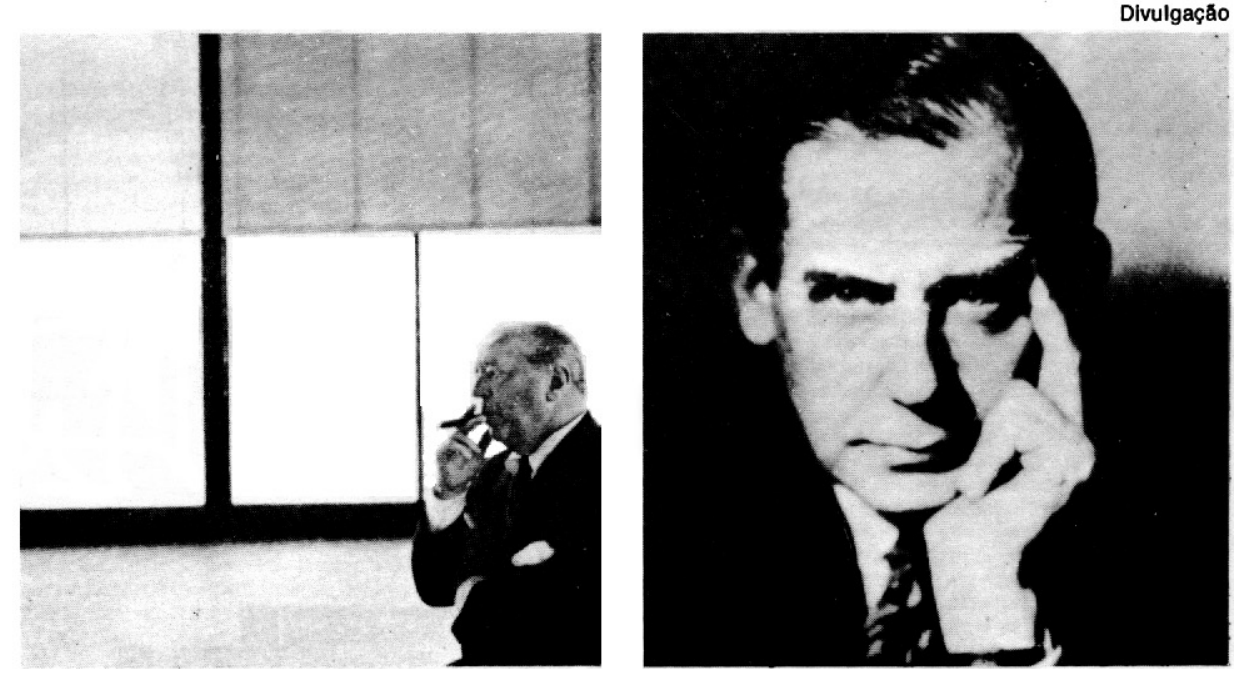

A última trincheira já se armava. Mais um contra-ataque, só que agora era doméstico. Agora eram "os Venturi" contra os "brancos". O relato de Wolfe mostra que a discussão perdeu força. Alguns resvalam na mesquinharia e nas acusações pessoais. Mas, em meio a esta disputa pela "alma do Movimento Moderno", constatou-se, para espanto geral, que os americanos estavam tomando das mãos dos europeus a vanguarda. E o mais surpreendente, a vanguarda teórica!

Esta conquista consolidou-se na década de 80 através de uma nova forma de organjzação, os "redutos empresariais". Ali se combinam as duas vertentes da competição moderna - "a construção de edifícios e a teorização da arquitetura - numa única entidade". Os "redutos emprésariais" que mais se destacaram nesta fase são: Arquitetonica, a SITE e a Friday Architects.

O livro termina como terminam os livros que narram uma história viva, isto é, dão a entender que fatos novos estão chegando, mas que para narrá-los é preciso esperar um pouco, observá-los. Esperar que ganhem sentido histórico, que se integrem.

Uma frase chama a atenção nas últimas páginas e tem força de conclusão. Sempre em tom de caçoada Wolfe dispara: "Para o arquiteto ambicioso ter uma teoria tornou-se tăo vital e natural quanto ter um telefone". E é bom lembrar que a maioridade, a autonomia tão ambicionada pelo próprio Wolfe, da arquitetura americana, só se realizou quando Venturi e mais tarde os neopuristas partem para o coração dos redutos, isto é, para a disputa teórica. Não bastaram os edifícios, era necessário incluir a reflexão teórica. Wolfe faz troça de grande parte desta reflexão produzida mas reconhece que sua presença foi essencial. 